Kobayashi, 1934 (Order Nautiloidea) and Damesites Matsumoto, 1942 (Order Ammonoidea), validation (Cl. Cephalopoda). Proposals are also made for the adoption of declarations : (1) clarifying $(a)$ the provisions of the "Code of Ethics", $(b)$ the procedure to be adopted when a specific name is published in an abbreviated form and $(c)$ the status of names published in works written in Latin; (2) determining the gender to be attributed to generic names with the terminations '-ides', '-ites' and '-oides'. Comments should be sent as soon as possible in duplicate to Francis Hemming, Secretary to the Commission. 28 Park Village East, Regent's Park, London, N.W.1.

\section{Physics of Non-Destructive Testing}

UNDER the title "Physics of Non-Destructive Testing", Supplement No. 6 to the British Journal of Applied Physics, published recently by the Institute of Physics, contains a selection of papers chosen from those presented during the past year at meetings of the Non-Destructive Testing Group. The technology of non-destructive testing is usually regarded as being confined to the task of detecting defects in materials and components. The detection of defects, however, forms a relatively small part of the whole subject for, if the term 'non-destructive testing' is taken in its broadest sense, it includes every type of nondestructive measurement carried out on solids, liquids and gases, with the object of examining some aspect of their physical, chemical and even biological condition. Very little is to be found in Supplement No. 6 about the physical principles upon which present-day techniques for detecting defects are based. Indeed, the one discussion reported dealing with this aspect of the subject serves to show that, in the particular case of the penetrant method for flaw detection, practically nothing is understood about the mechanism involved when a fluid penetrates a crack. The supplement records some of the current scientific investigations which are likely to yield the kind of knowledge required for the development of new types of testing technique. The information reported directs attention to the scientific background from which automatic systems of quality control will be created. There are papers dealing with the relationship between the structure of materials and their physical properties. Some papers are concerned with the measurement of those physical properties which would serve to detect changes in structure and composition of materials. Two papers describe studies of structural changes accompanying metal fatigue and discuss the possibility of detecting these changes by means of a physical property (damping capacity). A unique feature of the Supplement is that it contains a contribution entitled "Physical Methods in Medical Diagnosis". The medical field is one in which non-destructive testing is of particular interest.

\section{Volcanism in Asia}

E. M. Murzaev (Priroda, No. 3, 90; 1957) has assembled a record of new discoveries of recent volcanicity in Siberia and Central Asia. There is a considerable body of evidence to show a very large extent of Quaternary volcanism in eastern Siberia and eastern and central Mongolia. Certain volcanoes were active in northern Manjouria in the eighteenth century. E. M. Murzaev, V. A. Obruchev and V. I. Vlodavetz have described well-preserved volcanic cones and lava flows in the Khingan and Darigang regions of Mongolia. Various travellers have also reported on volcanoes of Kuen-Lun and northern Tibet. There are also reports on active volcanoes in the Chinese provinee of Sintzian and other parts of China. In Tian-Shan and Pamir only voleanic rocks connected with fissure eruptions are known, and there are no traces of Quaternary volcanicity.

\section{Polish Ephemerides}

Rocznik Astronomiczny Obserwatorium Krakowskiego, 28 (1957), contains the ephemerides of eclipsing binaries, prepared by Dr. K. Kordylewski and his collaborators at Cracow Observatory. The present ephemerides contain 705 stars, a considerable increase over the 589 stars listed in the issue for 1956. At the end of the publication, tables of processional coefficients and of obliquity of the ecliptic, and also of occultations of stars by the Moon, are given. 'The first of these enables, by the use of simple formula, the calculations of the reduction of rectangular equatorial co-ordinates from the epoch $1957 \cdot 0$ to another epoch, and vice versa. The first two were computed by Dr. S. Andruszewski and the occultation tables by W. Wiśniewski, using T. Banachiewicz's method. The computations were made for the five Polish Observatories of Poznán, Wroclaw, 'Torun, Cracow and Warsaw.

\section{Microchemical Journal}

THe first number of a new publication, Microchemical Journal, devoted to the application of microtechniques in all branches of science, has been received. It has an editorial board of well-known authorities and is published under the auspices of the Metropolitan Microchemical Society by Interscience Publishers, New York and London. The subscription price is 9.60 dollars per year, foreign postage 0.50 dollar per volume. The first part contains some interesting original papers and also brief abstracts of publications in the field. We wish the new journal every success.

\section{Meeting of Nobel Prize-winners in Lindau}

THE annual meeting of Nobel Prize-winners is to be held in Lindau, Lake Constance, during July 1-5. The conference, which will be held in the Stadt. theater, Lindau, will be devoted to various aspects of medicine, and the following addresses will be delivered: Prof. P. S. Hench (Rochester), "The Chemical and Experimental Uses of Cortisone"; Prof. Werner Forssmann (Bad Kreuznach), "Über Cardiologie"; Prof. Henrik Dam (Copenhagen), "Über einige Ernährungsversuche mit dem Goldhamster" ; Prof. W. M. Stanley (Berkeley), "Relations between Viruses and Cancer"; Prof. Georg von Hevesy (Stockholm), "Krebsanaemie" ; Prof. Gerhard Domagk (Wuppertal-Elberfeld), "Stand der Chemotherapie des Carcinoms" ; Prof. Selman A. Waksman (New Brunswick), "Antibiotics and their Social Significance"; Dr. Paul Hermann Müller (Basle), "Antibiotica in der Landwirtschaft"; Prof. Hans von Euler-Chelpin (Stockholm), "Anpassung und Resistenz"; Prof. Hugo Theorell (Stockholm), "Atmungsfermente" ; Prof. Richard Kuhn (Heidelberg), subject to be announced. Also participating will be Prof. Kurt Alder (Cologne), Prof. Max Born (Bad Pyrmont) and Prof. Adolf Butenandt (Munich). The meeting will be of general interest to both medical practitioners and research workers, and opportunities will be provided for discussion. A comprehensive programme of excursions has also been arranged. Further details may be obtained from 